\title{
Epidemiology and risk factors for gallstones in the paediatric and adult population in the city of Al-Ahsa
}

\author{
samia alfuraikh $^{1}$, sara algubaisi ${ }^{2}$, lubna ALhamad ${ }^{1}$, and Khadiga Mahmoud Hussein ${ }^{1}$ \\ ${ }^{1}$ King Abdulaziz Hospital \\ ${ }^{2}$ Prince Sultan Military Medical City
}

July 9,2021

\begin{abstract}
Background and Aims: Cholelithiasis is a common upper gastrointestinal tract disorder in the Kingdom of Saudi Arabia. Analyses of risk factors for gallstone formation may explain the need for lifestyle modifications. Therefore, our aim was to identify sex- and age-related differences in the prevalence and risk factors for gallstones among Saudi individuals in the city of Al-Ahsa. Methods: The medical records of patients, [?]1 year of age, with a radiologically confirmed diagnosis of gallstones, between 2014 through 2016, were retrieved and relevant demographic and clinical data extracted. Risk factors for cholelithiasis for all age groups were identified. Results: A total of 618 patients had radiologically confirmed gallstones over the 3-year period of observation. The prevalence was higher among females than males ( $73 \%$ versus $27 \%$, respectively) in all age groups. In the paediatric group, the prevalence of gallstones was higher among girls with obesity and those with sickle cell disorders. Advanced age, a higher body mass index, high low-density lipoproteins, triglycerides, and cholesterol were independently associated with cholelithiasis in both gender of all age groups. Hepatitis B and $\mathrm{C}$ were not found to be risk factors for cholelithiasis. Conclusions: Older age, female sex, a high body mass index, and hyperlipidaemia are major risk factors for gall stones formation among all age groups. Haemolytic anaemia, namely sickle cell disease, is a prevalent risk factor in paediatric population.
\end{abstract}

\section{Introduction}

An imbalance in the chemical constituents of bile components can result in the formation of gallstones of varying size and shape ${ }^{[1]}$. Cholesterol supersaturation, gallbladder dysfunction and nucleation defect play key roles in the pathogenesis of gallstone formation ${ }^{[2]}$. Gallstones are classified into pure cholesterol stones, pigment stones, and mixed composition stones ${ }^{[1,2]}$. Cholesterol stones are yellow in colour, more commonly found in adults, and might dissolve with bile acid therapy ${ }^{[3]}$. Pigment stones are classified into brown or black types. Black pigment stones are more common in patients with liver cirrhosis or chronic haemolytic anaemias $^{[4]}$.

Epidemiological studies have revealed geographical influences on the prevalence rate of gallstones ${ }^{[5,6]}$. Worldwide, there appears to be higher rates of cholelithiasis in Western Caucasian, Hispanic, and Native American populations, with the rates being lower among East European, African American, and Asian populations ${ }^{[6]}$.

The prevalence of gallstones in the Kingdom of Saudi Arabia (KSA), however, has not been well established to date and may in fact vary from region to region across the KSA ${ }^{[7]}$. In 2007, community-based study of the Asir region of the KSA, Abu-Eshy et al. reported a prevalence rate of $11.7 \%^{[8]}$. In 2014, Alawad et al. reported a prevalence rate of $10.9 \%$ in the Hail region of the northern KSA. ${ }^{[9]}$. A screening of 1018 patients by using ultrasound, identified a prevalence rate of $23 \%$ in the city of $\mathrm{Al}$ Madina. ${ }^{[10]}$. A cross sectional study performed in the city of Riyadh in 2017 reported a prevalence rate of gallstones of $8.6 \%$ [11].

Numerous adult studies have reported an association between the development of cholesterol gallstones and the following factors: obesity, a western diet, type 2 diabetes, metabolic syndrome, advanced age, female sex, 
parity, rapid weight loss, oestrogen therapy, total parenteral nutrition, genetic factors, and ethnicity ${ }^{[12]}$. By contrast, pigmented stones are principally caused by haemolytic blood disorders, such as sickle cell disease. The highest estimated prevalence of sickle cell disease in the KSA is in the eastern region ${ }^{[13]}$. A premarital screening program identified a prevalence rate in adult population for sickle cell trait (SCT) of $17 \%$ and $1.2 \%$ for sickle cell disease (SCD), while a new born screening program reported $21 \%$ for SCT and $2.6 \%$ for SCD in eastern province ${ }^{[14]}$. Considering that $50-85 \%$ of patients with sickle cell anaemia will develop pigmented gallstones ${ }^{[15]}$, the population of Al-Ahsa, a large oasis located in the eastern province of the KSA, would be at highest risk for gallstones in the KSA ${ }^{[16]}$.

Our aim in this study was to identify the prevalence and risk factors for gallstones in the city of Al-Ahsa, based on age and sex and to find if haemolytic anemia is a risk factor in all age group. To the best of our knowledge, no previous study has systematically analysed the relationship between sex- and age-related risk factors and gallstone formation.

\section{Methods and Materials}

Statement of ethics

The study protocol was approved by International Medical Research Centre Scientific Committee (SP 17/036/A), and the Institutional Review Board (IRBC/354/17).

Study design

We conducted a retrospective chart review among patients, [?]1 year of age, with radiologically confirmed cholelithiasis at King Abdul Aziz Hospital (KAH) in the city of Al-Ahsa. The data collected for three consecutive years, 2014, 2015, and 2016, using electronic and manual medical records. Excluded were patients under the age of 1 year, as well as those with primary anatomic abnormalities of biliary system, with ultrasound confirming biliary sludge without gall stones, and patients with incomplete data.

The following demographic (age, sex, weight, and height) and biochemical parameters (lipid profile, serum amylase level, hepatitis B and C serology, sickle cell test, and electrophoresis) were extracted from the charts. Medical and social histories were screened for medication, smoking, alcohol use, and the presence of other comorbidities, such as diabetes and thyroid disease. For analysis, patients were classified based on their age and body mass index (BMI). Age was classified into the following three groups: group 1, 0-18 years; group 2, 19-60 years; and group 3, >60 years. The World Health Organization (WHO) classification of BMI was used, as follows: overweight, $25[?] 0-29[?] 9 \mathrm{~kg} / \mathrm{m} 2$, or obese, [?] $30 \mathrm{~kg} / \mathrm{m} 2$.

Sample size was calculated using the following formula: $N=$ (Z1-Alpha) $2 \times(p q) / E$. For this sample size calculation, we used the previously published prevalence rate of cholelithiasis among Saudi population of $11.7 \%{ }^{[8]}$, at power of 0.80 and margin of error of 0.05 . Taking into consideration a rate of missing variables in the medical charts of $50 \%$, a sample size of 480 patients would be necessary to identify predictive factors for gallstones. After screening, we included 636 patients in our study group.

Statistical analysis

Descriptive statistics (mean and standard deviation, or count and frequency) were used for the following variables: sex and age distribution; height, weight and the calculated BMI; hepatitis B and C status; presence or absence of sickle cell disorders; total serum levels (with normal cut offs indicated) of cholesterol ([?]5.2 $\mathrm{mmol} / \mathrm{L}$ ), high-density lipoproteins (HDL, 1.0-1.3 mmol/L), low-density lipoproteins (LDL, [?]2.59 mmol/L), amylase (40-140 U/L), and triglyceride (TG, [?]1.7 mmol/L); and thickness of the gall bladder wall $(<3 \mathrm{~mm})$.

Multivariate logistic regression analyses were used to identify significant independent risk factors for cholelithiasis. The odds ratio (OR), and associated 95\% confidence interval (CI), for cholelithiasis was calculated for each independent factor, adjusted for sex and age. $\mathrm{p}$ value $<0.05$ was considered significant.

All analyses were performed using SPSS (version 20, IBM, Chicago, IL, USA).

\section{Results}


Of the 643 patients, with radiological confirmation of gallstones, enrolled into our study, 25 patients were excluded due to missing data, with the final analysis being based on the data of 618 patients, 185 males and 433 females. The age, gender, and BMI distribution of our study cohort is shown in Table 1.

The following groups were formed for analysis: group 1, 45 paediatric patients, with a mean age of $12.2 \pm 7.08$ years of girls and 12.6 \pm 5.52 years for boys; group 2, 509 middle-age adults, with a mean age of $38.7 \pm 10.4$ years for women and $37.9 \pm 10.4$ for men; and group 3, 64 older patients ( $>60$ years of age), with a mean age of $71.6 \pm 8.13$ for women and $73.8 \pm 9.99$ years for men.

\section{Distribution by BMI}

The distribution of patients in each age group (groups 1 through 3 ) by BMI classification is shown in Table 1. About $42 \%$ of patients in group 1 (paediatric group) were obese (BMI [?] $30 \mathrm{~kg} / \mathrm{m} 2$ ) and $20 \%$ were overweight (BMI, $25-29.9 \mathrm{~kg} / \mathrm{m} 2$ ). In group 2 (middle-age adults), $55 \%$ were obese and about $34 \%$ were overweight. In group 3 (older patients), $44 \%$ were obese and $37.5 \%$ were overweight. Across all three groups, a BMI [?] $30 \mathrm{~kg} / \mathrm{m} 2$ (obese) was more frequent among females than males, respectively, as follows: group 1, $45.4 \%$ versus $33 \%$; group $2,58 \%$ versus $48.7 \%$; and group $3,46 \%$ versus $40 \%$. These sex-specific differences in the proportion of obese individuals were all significant.

\section{Distribution by lipid profile}

The distribution of patients in each age group by their lipid profile is shown in Table 2. Of note, this information was available for a smaller number of patients in each age group, as follows: 14 patients in group 1 (paediatric), 212 in group 2 (middle-age adults), and 34 in group 3 (older patients).

In group 1, 57\% of patients had a high cholesterol level, with $43 \%$ having a high TG level in each gender. HDL levels were low in $14.3 \%$ of males and $43 \%$ of females tested in group 1, with LDL levels being high in $28.6 \%$ of males and $57 \%$ of females tested.

In group 2, lipid profiles were available for 69 of the 148 male patients; high cholesterol level was identified in $83 \%$, and high TG level in $86 \%$. LDL level was high in $55 \%$, and a HDL level $<1.3 \mathrm{mmol} / \mathrm{L}$ in $72.5 \%$. For women, lipid profiles were available for 143 of 361 patients enrolled, with high cholesterol identified in 94\%, with high TGs in $93 \%$, high LDL in $73 \%$, and low HDL in $50 \%$.

In group 3, lipid profiles were available in 11 of 25 men, with $91 \%$ of these men having high cholesterol, $82 \%$ had a TG level $>1.7 \mathrm{mmol} / \mathrm{l}, 55 \% \mathrm{LDL}>2.59 \mathrm{mmol} / \mathrm{L}$, and $64 \%$ a HDL $<1.3 \mathrm{~m} \mathrm{~mol} / \mathrm{L}$. Lipid profiles were available in 23 of the 39 women in this group, with $70 \%$ of these women having high cholesterol, $74 \%$ high TG values, $74 \%$ high LDL, and $65 \%$ low HDL.

\section{Proportion of the population with haemolytic anaemia}

The prevalence and distribution of haemolytic anaemia is shown in Table 3. In group 1, 25\% of boys and $30 \%$ of girls tested positive for sickle cell disease. In group 2, this proportion decreased $5.8 \%$, with no significant differences between-sex, while in group 3, of the 40 patients who underwent testing, only 1 man tested positive.

\section{Distribution by viral hepatitis status}

The distribution of patients who tested positive for HBV or HCV is shown in Table 3. None of the 20 patients in group1 tested positive for HBV, and only 1 girl had positive serology for $\mathrm{HCV}$. In group 2, HBV screening was performed in 378 patients, with a positive serology in 9 patients (2.4\%). HCV screening was performed in 267 patients, with a positive serology identified in 2 women (1\%). In group 3, none of the patients tested showed positive serology for HBV; while for HCV, of the 34 women tested, a positive serology was identified in $3(8.8 \%)$.

\section{Complications and outcome of gallstones}


With the exception of 43 patients, all others required cholecystectomy. Cholecystectomy was performed laparoscopically in the majority of patients, with only 4 required an open approach, with one of these being a case of conversion from laparoscopic to open. Bariatric surgery was performed at the same time in 6 patients. Post-cholecystectomy recovery was unremarkable in all patients, with no significant morbidity and no incidence of mortality.

At time of presentation, biliary pancreatitis, with high serum amylase level, was evident in half $(50 \%)$ of the females and $44 \%$ of the males in group 1 (paediatric). In group 2, $65 \%$ of 100 males, compared to $55 \%$ of 210 females, presented with an elevation of serum amylase. In group 3, a high serum amylase level was identified in $87.5 \%$ of males and $72 \%$ of females.

Cholecystitis, identified by a thickening of the gall bladder wall (GBWT) on ultrasound, was identified in 5 children (one male $8.3 \%$ and 4 females $12.1 \%$ ), compared to $72 \%$ of women and $8 \%$ in Men in group 2. $28 \%$ of women and $18 \%$ of men in group 3 showed GBWT.

\section{Comparison of risk factors among males and females Table- 4}

In the male population, the binary multivariate logistic regression analyses showed significant association of gall stone with the following variables; advancing age (OR 0.403, 95\% CI 0.23-0.72, $\mathrm{P}=0.002$ ), Obesity (OR $0.51,95 \%$ CI $0.32-0.83, \mathrm{P}=0.006$ ), triglycerides (OR $0.464,95 \%$ CI $0.257-0.837, \mathrm{P}=0.011$ ), LDL (OR $1.683,95 \%$ CI 1.159-2.445, $\mathrm{P}=0.006$ ); sickle cell anemia (OR15.31, 95\% CI 3.60- 65.04, $\mathrm{P}=0.001$ ). While no significant association with Total cholesterol (OR1.024, 95\% CI 0.649- 1.616, $\mathrm{P}=0$. 91) and HDL (OR0.639, $95 \%$ CI $0.140-2.909, \mathrm{P}=0.563)$.

Hepatitis B and hepatitis C were not found to be correlated with the prevalence of gall stones $(\mathrm{p}>0.05)$.

In the female population, the binary multivariate logistic regression analyses showed advancing age of 1960 years (OR 2.484, 95\% CI 1.39-4.43, $\mathrm{P}<0.002$ ), increased BMI (OR 1.95, 95\% CI1.393- 4.431, $\mathrm{P}<0.006$ ); elevated total serum cholesterol $(\mathrm{OR}=2.657 \mathrm{CI}$ of $0.999-7.067 \mathrm{P}=0.050)$; triglycerides (OR 2.156, CI 1.194 -3.892, $\mathrm{P}=0$.011),HDL (OR 2.57, CI 1.086- 6.109, $\mathrm{P}=0.032$ ); LDL (OR 5.478, CI 1.348-22.261, $\mathrm{P}=0.017)$ and sickle cell anemia (OR16.786, CI 3.965-71.064, $\mathrm{P}<0.0001)$ were significantly associated with the risk of cholelithiasis.

Hepatitis B and C were not significantly correlated with prevalence of gall stones ( $\mathrm{p}>0.05)$. (Table-3)

\section{Discussion}

The rising prevalence of gallstone disease in the Saudi population is a cause of concern. In 1990, an increase in the frequency of cholecystectomy in the eastern province of the KSA was noticed, which reflect the increase in the incidence of gallstones ${ }^{[17]}$. Transabdominal ultrasound provides the ideal diagnostic tool to accurately determine the prevalence of gallstone disease; a sit is a safe imaging technique with high sensitivity and specificity for gallstones ${ }^{[6]}$. In our study, we included patients with a diagnosis of gallstones confirmed by transabdominal ultrasound at $\mathrm{KAH}$ in Al-Ahsa city, over 3 consecutive years to evaluate the prevalence and sex- and age specific risk factors for cholelithiasis. The KAH is one of the Ministry of National Guard hospitals in the KSA that provides primary, secondary, and tertiary healthcare services to National Guard employees and their families, as well as eligible Saudi citizens referred from other hospitals. It has a total bed capacity of about 300 beds. Annually about 220 cholecystectomies are performed in our hospital, with $10 \%$ being paediatric cases. This is comparable to the data for King Fahad Hospital in Almadinah Almounawarah, with a 500-bedcapacity, where 400 cholecystectomies are performed on average per year ${ }^{[18]}$. We note that we excluded patients under the age of 1 year from our study as the aetiology of cholelithiasis in infants is unique, generally being related to congenital anatomical disorders, genetic diseases, ceftriaxone therapy, and total parenteral nutrition ${ }^{[19]}$. Gallstones in infancy can present with cholestasis, pale stools, sepsis, and abdominal pain but, more often, is asymptomatic and resolves spontaneously without surgical intervention ${ }^{[20]}$. Our findings of a higher prevalence of gallstones in females than males agree with previously published international observations which reported a 2-fold higher increase in the risk for gallstones in women compared to men ${ }^{[21-22-23]}$. Similarly, a higher prevalence among women than men has 
been reported for the KSA ${ }^{[8-9-10-11]}$. The underlying pathophysiology for gall stone formation in women could be related to effects of sex hormones on bile secretion and function of the gall bladder; this is supported by a specifically higher risk of gallstone formation after menopause and in post-menopausal women using oestrogen therapy ${ }^{[24-25-26]}$. These findings related to cholesterol stones, with the prevalence of pigmented stone being almost equal among both sex in countries where pigmented stone is more prevalent, as in Taiwan [27]. Female sex was also found to be a risk factor for gallstones in children, where $73 \%$ of cases in our paediatric population were girls. Again, this finding agrees with previously published data ${ }^{[28]}$. Obesity and overweight are well recognized for their strong association with gallstone disease. People with obesity have a higher incidence of cholelithiasis, cholecystitis, and cholesterolosis compared to lean individuals ${ }^{[29]}$. In our study group, obesity was a strong risk factor for gallstone formation in both paediatric and adult patients. Our findings also suggest that the epidemic of obesity in Saudi children has contributed significantly to the striking increase in paediatric gallstone disease. This concurs with the findings of Mehta et al. who reported that a strong association between paediatric gall bladder cholelithiasis and obesity $(\mathrm{P}=0.03)[28]$. In our study a higher BMI among adults was the most important preventable risk factor that appears to largely account for the high prevalence of gallstone (Pvalue 0.05). In good agreement with our study, Hung et al., in their population-based case control study, reported obesity to be a strong predictor for the development of gallstones (OR 1.89, 95\% CI 1.18-3.04, $\mathrm{Pl}=0.008)$, with women being at a higher risk for gallstones than men (OR 1.91, 95\% CI 1.07-3.41, $\mathrm{P}=0.030)^{[30]}$. Analogous findings were reported by in a Mendelian randomized study that showed that an increase BMI among women was a causative factor for cholelithiasis $(\mathrm{P}=0.001)$ [31]. It has been reported that 20-30\% of all gallstones in children are due to haemolytic diseases such as sickle-cell disease, hereditary spherocytosis and thalassemia ${ }^{[32]}$. In $40-50 \%$ of paediatric cases, the underlying cause of gallstones is due to another known aetiology, including total parenteral nutrition, prolonged fasting, ileal disease or ileal resection, frusemide therapy, congenital biliary diseases, such as a choledochal cyst, chronic liver disease and progressive familial intrahepatic cholestasis (PFIC). Around $30-40 \%$ of cases are idiopathic in nature ${ }^{[20]}$.

Gallstone is a common complication in children with haemoglobinopathies because of the recurrent episodes of haemolysis leading to an increase in bilirubin excretion and pigment gallstones formation. The development of pigment gallstones in patients with sickle cell disease is largely age-dependent, with $15 \%$ of cases being in children \&lt;10 years of age, $22 \%$ in children 10-14 years of age, and 36\% in children 15-18 years of age, with a reported prevalence of $50 \%$ by the age of 22 years ${ }^{[33]}$. Our study findings revealed a noteworthy relationship between gallstone formation and sickle cell anemia among paediatric patients, with girls being at higher risk than boys (30.3\% versus 25\%). The findings from the Howard University Centre for Sickle Cell Disease study agreed with our findings, with gallstones reported in $70.6 \%$ of girls with sickle cell anaemia, compared to $55.1 \%$ in boys ${ }^{[34]}$. While Dooki et al. reported a lower rate of cholelithiasis among children with haemolytic anaemia of $13.6^{[35]}$, Chabchoub et al from Tunisia reported similar prevalence to our study with $36.8 \%$ of paediatric patients with gallstones had haemolytic anaemias. ${ }^{[36]}$. By contrast, in our adult group, males with sickle cell disorders were at a higher risk for gallstones than females. A retrospective review by Martin et al. ${ }^{[37]}$ reported that $25.7 \%$ of adult patients with sickle cell disease presented with an increased incidence of gallstone formation. Analogous findings were reported by Gumerio et al., with an incidence rate of gallstone formation of $45 \%$ among patients with sickle cell-haemoglobin C disease and heterozygous sickle cell disease/beta-thalassemia (S $\beta$ ), with the average age of onset of cholelithiasis in this group being 12.5 years ${ }^{[38]}$. Laparoscopic cholecystectomy is the treatment of choice in children with clinically symptomatic disease, with the best treatment option for asymptomatic cases being a source of debate ${ }^{[39]}$. As an example, whereas the Brazilian study ${ }^{[37]}$ and the Jamaican study ${ }^{[40]}$ recommended conservative management for asymptomatic children due to lack of significant complications over a period of observation of 8 years, other investigators still recommend elective cholecystectomy as the gold standard therapy in children with sickle cell disease with asymptomatic cholelithiasis to prevent potential complications, such as cholecystitis and choledocholithiasis, as well as postoperative complications (sickle cell crisis) when emergency cholecystectomy is performed ${ }^{[37]}$.

In our analyses, high serum cholesterol $(\mathrm{p}=0.027)$, TG $(\mathrm{P}=011)$, and LDL $(\mathrm{P}=0.006)$, and low HDL $(\mathrm{P}=0.03)$ 
were associated with a higher risk of gallstones, particularly among women. These findings were in good agreement with previous cross-sectional and prospective investigations ${ }^{[41,42]}$. A population-based study conducted in China by Andreotti et al. ${ }^{[42]}$ reported that high serum levels of TG and low levels of HDL were associated with an elevated risk for biliary stones, as well as biliary tract cancer. Malik et al. [43] agreed that the prevalence of cholelithiasis was higher among women than men with a hyperlipidaemic profile $(80 \%$ versus $71.42 \%$ ). This study also revealed that hypercholesteremia was the most common abnormality in both sexes, followed by hypertriglyceridemia, and that lipid profiles improved up to 6 months after cholecystectomy, but that HDL remained unchanged. A spectrometric study further supported these findings, reported a linear correlation between high cholesterol and the rate of gallstones $(\mathrm{P}=0.05)$, with a similar linear correlation for LDL levels (P\&lt; 0.001) ${ }^{[44]}$. Bhatti et al. reported strong relationship between gallstone formation and a fatty liver, particularly among adult females ${ }^{[41]}$. The occurrence of cholelithiasis was not associated with either hepatitis B or C infection in our study. Analogous findings were reported in a systemic literature review, indicating a null relationship between hepatitis B infection and cholelithiasis [45]. Of note, a community-based study in Taiwan did report a positive linear relationship between gallstone formation and hepatitis $\mathrm{C}$, but not $\mathrm{B}$, among males ${ }^{[46]}$. Our findings could be explained by the fact that the prevalence of hepatitis B is rapidly declining in the KSA due to the premarital screening program and efficacy of the immunization program by our national health organization. Finally, we did identify that $13.4 \%$ of our patients in the 2015 had type 2 diabetes, with a comparable prevalence rate of $10 \%$ in 2016 . We note that $25.5 \%$ of patients in both years used Calcium and vitamin D supplementation for not less than 2 months prior to surgery. Data for 2014 was incomplete regarding this information.

\section{References}

1. Njeze GE. Gallstones. Niger J Surg 2013; 19:49-55.

2. Al Mofleh IA. Gallstones. Saudi J Gastroenterol 1995; 1:173-9

3. Di Ciaula A, Wang DQ-H, Wang HH, Bonfrate L, Portincasa P. Targets for current pharmacological therapy in cholesterol gallstone disease. Gastroenterol Clin North Am 2010; 39: 245-ix.

4. Stewart L, Oesterle AL, Erdan I, Griffiss JM, Way LW. Pathogenesis of pigment gallstones in Western societies: the central role of bacteria. J Gastrointest Surg 2002; 6:891-903; discussion 903-4.

5. Chang YR, Jang JY, Kwon W, Park JW, Kang MJ, Ryu JK, Kim YT, Yun YB, Kim SW. Changes in demographic features of gallstone disease: 30 years of surgically treated patients. Gut Liver 2013; $7: 719-24$.

6. Stinton LM, Shaffer EA. Epidemiology of gallbladder disease: Cholelithiasis and cancer. Gut Liver 2012; 6:172-87.

7. Zahrani IH, Mansoor I. Gallbladder pathologies and cholelithiasis. Saudi Med J 2001; 22:885-9.

8. Abu-Eshy SA, Mahfouz AA, Badr A, El Gamal MN, Al-Shehri MY, Salati MI, Rabie E. Prevalence and risk factors of gallstone disease in a high-altitude Saudi population. East Mediterr Health J 2007; 13:794-802.

9. Alawad MN, Almotlaq AM, Alorf SH, Alshammari NH, Almhannaa AM, Aljohani HM, Elsayed MI. Ultrasound prevalence of gallbladder disease in Hail, Saudi Arabia, Int J Sci Res 2014;5:611.

10. Alshoabi S. Gallstones: Site, size, number, prevalence and complications by ultrasonography. Int J Med Imag 2016; 4:52-6.

11. Alishi YA, Howaish FA, Alhamdan FA, Almalki AA, Algahtani SA, Alharthi SA, Alanazi AS, Alsuroji AHS. Prevalence and risk factors for gallstone s among population in Riyadh City, KSA 2017. Egypt J Hosp Med 2017; 69:2384- 88.

12. Pak M1, Lindseth G. Risk factors for cholelithiasis. Gastroenterol Nurs 2016; 39:297-309.

13. Al Qurashi MM, El-Mouzan MI, Al-Herbish A, Al-Salloum A, Al-Omar A. The prevalence of sickle cell disease in Saudi children and adolescents. A community-based survey. Saudi Med J 2008; 29:1480-3.

14. Jastaniah W. Epidemiology of sickle cell disease in Saudi Arabia. Ann Saudi Med 2011; 31:289-93.

15. Al-Mulhim AS, Al-Mulhim AA. Laparoscopic cholecystectomy in 427 adults with sickle cell disease: a single-center experience. Surg Endosc 2009; 23:1599-602.

16. The Saudi Network http://www.the-saudi.net/saudi-arabia/saudi-informations.htm 
17. Tamimi TM, Wosornu L, al-Khozaim A, Abdul-Ghani A. Increased cholecystectomy rates in Saudi Arabia. Lancet. 1990; 336:1235-7.

18. Ahmed AF, El-Hassan OM, Mahmoud ME. Risk factors for gallstone formation in young Saudi women: A case control study. ASM 1992; 12:395-9.

19. Debray D, Pariente D, Gauthier F, Myara A, Bernard O. Cholelithiasis in infancy: a study of 40 cases. J Pediatr 1993; 122:385-91.

20. Poddar U. Gallstone disease in children. Indian Paediatr 2010; 47:945-53.

21. Völzke H1, Baumeister SE, Alte D, Hoffmann W, Schwahn C, Simon P, John U, Lerch MM. Independent risk factors for gallstone formation in a region with high cholelithiasis prevalence. Digestion 2005; 71:97105.

22. Parambil SM, Matad S, Soman KC. Epidemiological, demographic and risk factor profile in patients harbouring various types of gallbladder calculi: a cross sectional study from a south Indian tertiary care hospital. Int Surg J 2017; 4:525-8.

23. Shaffer EA. Epidemiology and risk factors for gallstone disease: has the paradigm changed in the 21st century? Curr Gastroenterol Rep 2005; 7:132-40.

24. Cirillo DJ, Wallace RB, Rodabough RJ, Greenland P, LaCroix AZ, Limacher MC, Larson JC. Effect of oestrogen therapy on gallbladder disease. JAMA 2005; 293:330-9.

25. Simonsen MH, Erichsen R, Frøslev T, Rungby J, Sørensen HT. Postmenopausal estrogen therapy and risk of gallstone disease: a population-based case-control study. Drug Saf 2013; 36:1189-97.

26. Wang S, Wang Y, Xu J, Chen Y. Is the oral contraceptive or hormone replacement therapy a risk factor for cholelithiasis? A systematic review and meta-analysis. Medicine 2017; 96: e6556.

27. Chen CH, Huang MH, Yang JC, Nien CK, Etheredge GD, Yang CC, Yeg YH, Wu HS, Chou DA, Yueh SK. Prevalence and risk factors of gallstone disease in an adult population of Taiwan: an epidemiological survey. J Gastroenterol Hepatol. 2006; 21:1737-43.

28. Mehta S, Lopez ME, Chumpitazi BP, Mazziotti MV, Brandt ML, Fishman DS. Clinical characteristics and risk factors for symptomatic pediatric gallbladder disease. Pediatrics 2012; 129: e82-8.

29. Camilleri M, Malhi H, Acosta A. Gastrointestinal complications of obesity. Gastroenterol 2017; 152:1656-70.

30. Hung SH, Liao KF, Lai SW, Li CI, Chen WC. Risk factors associated with symptomatic cholelithiasis in Taiwan: a population-based study. BMC Gastroenterol 2011; 11:111.

31. Stender S, Nordestgaard BG, Tybjaerg-Hansen A. Elevated body mass index as a causal risk factor for symptomatic gallstone disease: a Mendelian randomization study. Hepatol 2013; 58:2133-41.

32. Holcomb GW Jr, Holcomb GW III. Cholelithiasis ininfants, children, and adolescents. Pediatr Rev1990; 11:268-74.

33. Currò G, Meo A, Ippolito D, Pusiol A, Cucinotta E. Asymptomatic cholelithiasis in children with sickle cell disease: Early or delayed Cholecystectomy? Ann Surg 2007; 245:126-9.

34. Alexander-Reindorf C, Nwaneri RU, Worrell RG, Ogbonna A, Uzoma C. The significance of gallstones in children with sickle cell anemia. JNMA 1990; 82:645-50.

35. Dooki M-RE, Norouzi A. Cholelithiasis in childhood: A cohort study in north of Iran. Iranian J Pediatr 2013; 23:588-92.

36. Chabchoub I, Bouraouia I, Maaleja B, et al. Cholelithiasis in children: A single centre experience. Arab J Gastroenterol 2010; 11: 215-218

37. Martins RA, Soares RS, Vito FBD, de Fatima Barbosa V, Silva SS, Moraes-Souza H, Martins PRJ. Cholelithiasis and its complications in sickle cell disease in a university hospital. Revista Brasileira de Hematologia e Hemoterapia 2017; 39:28-31.

38. Gumiero APS, Bellomo-Brandão MA, Costa-Pinto EAL. Gallstones in children with sickle cell disease followed up at a Brazilian hematology center. Arq Gastroenterol 2008; 45:313-17.

39. Al Talhi Y, Shirah BH, Altowairqi M, Yousef Y. Laparoscopic cholecystectomy for cholelithiasis in children with sickle cell disease. Clin J Gastroenterol 2017; 10:320-6.

40. Walker TM, Hambleton IR, Serjeant GR. Gallstones in sickle cell disease: observations from the Jamaica Cohort study. J Pediatr 2000; 136:80-5. 
41. Bhatti AY, Waqar AB, Zia SA, Hussain N, Sulfiqar T. A cross sectional study on the risk factors of gallbladder stone. Int J Res Med Sci 2016; 4:5041-6.

42. Andreotti G, Chen J, Gao YT, Rashid A, Chang SC, Shen MC, Wang BS, Han TQ, Zhang BH, Danforth KN, Althuis MD, Hsing AW. Serum lipid levels and the risk of biliary tract cancers and biliary stones: A population-based study in China. Int J Cancer 2008; 122:2322-9.

43. Malik AA, Wani ML, Tak SI, Irshad I, Ul-Hassan N. Association of dyslipidaemia with cholelithiasis and effect of cholecystectomy on the same. Int J Surg 2011; 9:641-2.

44. Atamanalp SS, Keles MS, Atamanalp RS, Acemoglu H, Laloglu E. The effects of serum cholesterol, LDL, and HDL levels on gallstone cholesterol concentration. Pak J Med Sci 2013; 29:187-90.

45. Wijarnpreecha K, Thongprayoon C, Panjawatanan P, Manatsathti W, Ungprasert P. Hepatitis B virus infection and risk of gallstones: a systematic review and meta-analysis. Eur J Gastroenterol Hepatol 2016; 28:1437-42.

46. Dai C, Lin CI, Yeh ML, Hsieh MH, Huang CF, Hou NJ, Hsieh M, Huang JF, Lin ZY, Wang LY, Chang WY, Chen JS, Yu ML, Chuang WL. Association between gallbladder stones and chronic hepatitis C: ultrasonographic survey in a hepatitis C and B hyperendemic township in Taiwan. Kaohsiung J Med Sci $2013 ; 29: 430-5$.

\section{Hosted file}

tables.docx available at https://authorea.com/users/424789/articles/529799-epidemiology-andrisk-factors-for-gallstones-in-the-paediatric-and-adult-population-in-the-city-of-alahsa 